\title{
Changes in phytochemical contents in different parts of Clinacanthus nutans (Burm. f.) lindau due to storage duration
}

\author{
Ketaren Bunga Raya ('); Siti Hajar Ahmad ('); Sanusi Fatin Farhana ('); \\ Munirah Mohammad ('); Nor Elliza Tajidin ('); Anwar Parvez (2*) \\ (') Universiti Putra Malaysia - UPM, Department of Crop Science, Seri Kembangan, 43400, Selangor, Malaysia. \\ (2) Bangladesh Agricultural University - BAU, Department of Agronomy, Mymensingh, 2202, Bangladesh. \\ ${ }^{*}$ ) Corresponding author: parvezagron@yahoo.com
}

Received: Dec. 30, 2014; Accepted: May 8, 2015

\begin{abstract}
Clinacanthus nutans is a well recognized medicinal herb for its high phytochemical contents. Several aspects may contribute to the phytochemical contents, and thus determine the quality and efficacy of an herb. An experiment was conducted using a completely randomized design (CRD) with five replications, in a factorial arrangement of treatments. including two plant parts harvested at two different stages such as young leaves, young stems, matured leaves and matured stems, and four different storage durations such as 1, 2, 3 and 4 days. The study was aimed at determining how storage duration affects selected phytochemical contents of different plant parts of $C$. nutans at different harvesting stages. Total phytochemical content, total flavonoids content and DPPH radical scavenging activities are higher in young plants than in old plants, moreover, all those compounds are higher in leaves than in stems, and decrease gradually due to storage. Phytochemical, ascorbic acid and chlorophyll content of $C$. nutans differ among different plant parts and change due to storage. In general, young plant parts contain higher amount of phytochemicals, ascorbic acid and chlorophyll compared with matured parts confirming that phytochemicals content of $C$. nutans decreases when plants tend to maturity. Prolonged storage reduces phytochemical, ascorbic acid and chlorophyll content of $C$. nutans, which demands fresh use of this medicinal herb to avoid phytochemical losses. Further research focusing on the proper storage is necessary to minimize phytochemicals losses of C. nutans.
\end{abstract}

Key words: Clinacanthus nutans, postharvest, plant parts, harvesting period, storage duration, phytochemical content.

\section{INTRODUCTION}

Due to the increasing public awareness to being 'back to nature' for healthier life, the demands for herbal remedies have been growing for the last few decades. One of the medicinal herbs which is in increasing demands is Clinacanthus nutans, locally known as 'belalai gajah'or Sabah snake grass in Malaysia, which belongs to the family Acanthaceae. This species is widely grown in tropical Asian regions. As having medicinal effects, this plant has been widely used for remedial treatments in many countries including Thailand, Malaysia and China (Sakdarat et al., 2009; Sookmai et al., 2011). Some of its commonly known efficacies are in skin rashes treatment, snake and insect bites recovery, fighting herpes simplex virus (HSV), recovering varicella-zoster virus (VZV) lesions and viral infection (Chelyn et al., 2014). Besides, it also possesses anti-hepatitis, anti-herpes, and anti-inflammatory properties. Furthermore, this herb is also used to prevent and treat cancer (Sookmai et al., 2011; Wanikiat et al., 2008; Yong et al., 2013).
In medical perspective, the efficacious effect of medicinal plant is closely related to its phytochemical contents. Several studies regarding the phytochemicals of $C$. nutans are available, some of which are provided by Thisoda et al. (2006). The latter reported that the aerial parts of the plants, such as stem and leaves, are normally used for the extraction of active phytochemicals. C. nutans was found to have certain compounds that possess anti-herpes simplex activity able to inhibit anti-herpes simplex virus- $1 \mathrm{~F}$ activity at subtoxic concentration (Sakdarat et al., 2009). Therefore, the content of phytochemical in the herbal medicinal plants is very important since it determines the effectiveness of its usage in remedial purposes.

According to previous findings of medicinal herbs researches, there are some determining factors of the amount and types of phytochemicals content. Some researchers claimed that growth stage of plants contributes to the level of phytochemical content. Based on the finding of Zhang et al. (2010), during the early growth stage, leaves 
have low phenolic and flavonoids contents while the total alkaloids content gradually increases during the growth and development stages. Khan et al. (2009) confirmed that maturity stage affected the phytochemical content of Ipomoea mauritiana due to different bioactivities. Similarly, findings of Singh et al. (2010) are in agreement with that the stage of plant development contributes to the phytochemical contents. In addition, each plant part has different content of chemical substances, for example, total phenolic content and antioxidant composition of Urtica dioica L. vary with plant parts (Khare et al., 2012).

Another factor that is claimed to have an effect on the phytochemical content of medicinal plants is postharvest handling, such as storage duration, light exposure, insect and pathogenic attack and temperature during storage. Böttcher et al. (2003) reported that postharvest handling affected the quality of common Saint-John's wort herbs. Effective ventilation and cooling after harvesting is also essential to maintain common Saint-John's wort herbs quality. Another finding stated that there were losses and reduction in nitrates, oxalates and phenols in Vigna unguiculata during three months of storage compared to those before storage (Muchoki et al., 2010). According to Prabhu \& Barrett (2009), there was an increase in total phenolics of Cassia tora and Corchorus triden while the total chlorophyll contents decrease during storage. Furthermore, Singh \& Sagar (2010) reported that moisture content of curry and drumstick leaves increased during storage, irrespective of packaging material and storage period, and was less when stored at low temperature compared to room temperature.

Fresh leaves of C. nutans are highly demanded for the patients with cancer, diabetes and general ailments. Normally, the leaves are delivered in trucks without any proper cooling system, thus the products are exposed to warm temperatures during transport. In fact, the prolonged long delivery period of 4 days and warm temperature during transportation might cause the breakdown the phytochemical contents. Nevertheless, research findings on effect of different harvesting stages, various plant parts, as well as storage duration on the phytochemical contents of C. nutans are still meager. Therefore, lack of studies focusing on aforesaid aspects is the main concerned in this study. The study was therefore aimed at to determine how storage duration affects selected phytochemical contents of different plant parts of $C$. nutans at different harvesting stages.

\section{MATERIAL AND METHODS}

\section{Experimental site}

According to Koppen classification system, the

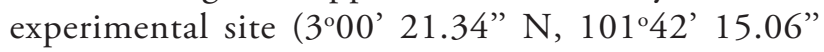
E, $37 \mathrm{~m}$ elevation) belongs to Tropical rainforest climate
(Af) which is characterized by constant high temperature $\left(18^{\circ} \mathrm{C}\right.$ or above) throughout the year, average precipitation of at least $60 \mathrm{~mm}$ in every month and no natural seasons. During the experimental period, monthly average maximum and minimum temperature and relative humidity ranged from 32.9 to $34.3{ }^{\circ} \mathrm{C}, 22.6$ to $23.1{ }^{\circ} \mathrm{C}$ and 92.7 to $96.8 \%$, respectively, while rainfall, evaporation and sunshine hours ranged from 4.6 to $11.8 \mathrm{~mm} /$ day, 3.8 to $4.2 \mathrm{~mm} /$ day and 6.77 to $7.51 \mathrm{hrs} /$ day, respectively.

\section{Experimental design and treatments}

The experiment was conducted using a completely randomized design (CRD) with five replications, in a factorial arrangement of treatments. Treatments included two plant parts harvested at two different stages such as young leaves (1 month old), young stems ( 1 month old), matured leaves (6 months old) and matured stems ( 6 months old), and four different storage durations such as 1, 2, 3 and 4 days. Total number of plants for each replication was five.

\section{Extraction process}

After three months of planting without shade in herbal farm, the plants of $C$. nutans were harvested at two stages for sampling and chemical analysis. In the first stage, the young leaves and young stems were harvested from upper aerial parts of the plants, while in the second stage, matured leaves and stems were picked up from the bottom aerial part. The samples were then washed with water, pre-cooled at $10^{\circ} \mathrm{C}$, packed in boxes lined with polyethylene and stored at $1,2,3$, and 4 days at $25^{\circ} \mathrm{C}$ to simulate transportation of fresh samples to local consumers. Then, the leaf and stem samples were analyzed for chlorophyll and phytochemical contents. The samples were chopped into small pieces, washed with liquid nitrogen, and ground with a mortar and pestle. Extraction and quantification of total phenolic and flavonoids contents, and radical scavenging activity assay (DPPH) were conducted as per standard methods. About $0.1 \mathrm{~g}$ of ground tissue samples was extracted with $10 \mathrm{~mL}$ of $80 \%$ ethanol and thoroughly shaken for two hours at $50^{\circ} \mathrm{C}$. After that, the mixture was filtered with filter paper Whatman ${ }^{\mathrm{TM}} \mathrm{N} .{ }^{\circ} 1$ to remove debris from the extract-containing ethanol. Finally, the ethanol was analyzed for total phenolic, total flavonoids contents and DPPH.

\section{Total phenolic and flavonoids content determination}

The amount of total phenolic in the herb extracts was determined with the Folin- Ciocalteau reagent using gallic acid as a standard. $200 \mu \mathrm{L}$ of the sample extract was mixed with Folin-Ciocalteau reagent $(1.5 \mathrm{~mL})$. Then, the mixture was allowed to stand at $22^{\circ} \mathrm{C}$ for 5 minutes before adding 
$\mathrm{NaCO}_{3}$ solution $\left(1.5 \mathrm{~mL}, 60 \mathrm{~g} \mathrm{~L}^{-1}\right)$. After two hours at $22^{\circ} \mathrm{C}$, absorbance was measured in a spectrophotometer at $725 \mathrm{~nm}$. The results were expressed as gallic acid equivalents (GAE/g of fresh sample). Flavonols was determined as the following. Initially, $1 \mathrm{~mL}$ of ethanol extract was mixed with $\mathrm{NaNO}_{3}(0.3 \mathrm{~mL})$ in a test tube covered with an aluminium foil and allowed to stand for 5 minutes. Then $10 \% \mathrm{AlCl}_{3}$ $(0.3 \mathrm{~mL})$ was added followed by addition of $1 \mathrm{M} \mathrm{NaOH}$ $(2 \mathrm{~mL})$. Finally, results were measured at $510 \mathrm{~nm}$ using a spectrophotometer (UV-3101P, LabomedInc, USA) with rutin as a standard (results expressed as $\mathrm{mg} \mathrm{g}^{-1}$ rutin fresh sample). The mean value of five representative plants was used to represent each replication.

\section{Radical scavenging activity assay (DPPH)}

To determine DPPH, $1 \mathrm{~mL}$ of extract was mixed with $2 \mathrm{~mL} \mathrm{DPPH}$ and allowed to stand for 3 minutes. Then, the solution was transferred to the cuvette and the absorbance was measured using spectrophotometer at $517 \mathrm{~nm}$. The equation for the percentage of inhibition was as follows (Equation 1):

Percentage of inhibition $=\frac{A A-A B^{*} 100}{A B}$

Where, $A A$ and $A B$ are absorbance of blank sample and extract, respectively.

\section{Ascorbic acid determination}

There are two methods in the determination of ascorbic acid content from the plant parts. The detailed procedures are described as follows. The first method began with the preparation of $3 \%$ metaphosphoric acid $\left(\mathrm{HPO}_{3}\right)$ in the following parts. An amount of 3\% metaphosphoric acid was added into $100 \mathrm{~mL}$ distilled water. Then the solution was kept cool in the fridge to avoid oxidation process. The next step was preparation for the standard of ascorbic acid solution and calculation of dye factor. A $0.1 \mathrm{~g}$ of ascorbic acid was added with $3 \%$ of metaphosphoric acid $\left(\mathrm{HPO}_{3}\right)$ to make up to the volume of $100 \mathrm{~mL}$. Then, $10 \mathrm{~mL}$ of the solution was diluted with $3 \%$ of metaphosphoric acid to the volume of $100 \mathrm{~mL}(1 \mathrm{~mL}=0.1 \mathrm{mg})$ as a standard for the ascorbic acid solution. Then, $5 \mathrm{~mL}$ of the standard solution was taken and added with $5 \mathrm{~mL}$ of $3 \%$ of metaphosphoric acid and the mixtures were titrated with the dye that had been prepared. The equation for the dye factor was as follows (Equation 2):

$$
\text { Dye factor }=\frac{0.5}{\text { volume of titrate }}
$$

The last step was preparing of dye solution. The dye solution was prepared by dissolving $0.021 \mathrm{~g}$ of sodium bicarbonate into $75 \mathrm{~mL}$ distilled water until the solution was dissolved.
Next, 0.025 g of sodium 2, 6-dichlorophenol-indophenol was dissolved into the solution and distilled water was added to make up to $100 \mathrm{~mL}$. The dye solution were kept cool and set aside. The standard procedure was prepared for each measurement. The second method was carried out as follows. First step was homogenizing and mixing $10 \mathrm{~g}$ of leaves sample with $40 \mathrm{~mL}$ of metaphosphoric acid by using a blender (MX-799S, Panasonic) for 1 minute at high speed and was filtrated by using cotton wool. Then, $5 \mathrm{~mL}$ from the titrate was transferred and titrated with dye solution until the solution turned to pink. The volume of the dye used was recorded. The equation to calculate the ascorbic acid was as follows (Equation 3):

$$
\begin{aligned}
& \text { Ascorbic } \cdot \text { acid }\left(\frac{m g}{100} g\right)= \\
& \frac{m L-\text { dye used } * \text { dye factor } * \text { vol. of product }(100 m L) * 100}{\text { weight of sample }(20 \mathrm{~g}) * \text { vol. of sample for titration }(5 \mathrm{~mL})}
\end{aligned}
$$

\section{Chlorophyll content determination}

The chlorophyll content was determined according to standard curve of SPAD value and destructive leaf of chlorophyll content relative to the reading of SPAD meter 502, Minolta Inc, USA. The samples were selected for analysis and total chlorophyll content was analyzed. The chlorophyll content was prepared by extracting $0.5 \mathrm{~g}$ of sample in $10 \mathrm{~mL}$ of $80 \%$ acetone. Then, the sample was centrifuged at $2500 \mathrm{rpm}$ for 5 minutes. Then, the extract was diluted by adding $9 \mathrm{~mL}$ of $80 \%$ acetone. The absorbance was measured at 664 and $647 \mathrm{~nm}$ using a spectrophotometer (UV-3101P, Labomed Inc.). The equation for total chlorophyll content was as follows (Equation 4):

$$
c c=\frac{\left(7.93 * O D_{664}+19.53 * O D_{647}\right) *\left(V_{C 3 H 60}\right)}{2\left(V_{C 3 H 60} \text { for OD reading }\right)} * \frac{1}{m_{\text {leaf }}}
$$

Where cc is chlorophyll content ( $\mathrm{mg} / \mathrm{g}$ fresh sample), O.D is 1 optical density, $\mathrm{V}_{\mathrm{C} 3 \mathrm{H} 6 \mathrm{O}}$ is total volume of $80 \%$ acetone, $\mathrm{m}_{\text {leaf }}$ is fresh sample $(\mathrm{mg})$.

\section{Statistical analysis}

The data were analyzed using analysis of variance (ANOVA) and means were compared by least significant differences at $\mathrm{p} \leq 0.05$ (SAS Version 9.2). Regression analysis was done to study the relationships between the effects of the treatments and the retention of phytochemicals. 


\section{RESULTS}

\section{Total phenolic content}

Total phenolic content of $C$. nutans was significantly influenced by plant parts, storage durations and their interactions (Table 1). It is evident from table 1 that, phenolic content was higher in young plant than in old plant. The highest phenolic contents were recorded in young leaves statistically followed by young stems. Matured stems, on the other hand contained the lowest phenolic compounds. Phenolic content of young leaves was $26 \%$ higher than that of matured leaves, and young stems contained $90 \%$ more phenolic compounds compared to matured stems. Total phenolic content was found to decrease gradually due to storage. Total phenolic content was reduced by almost $50 \%$ after 4 days storage. Figure 1 indicates that the total phenolic contents in different plant parts were significantly decreased after one day of storage at $25^{\circ} \mathrm{C}$. There were no significant differences $(\mathrm{p} \leq 0.05)$ regarding total phenolic contents between young leaves and young stems after day 2 until day 4 in storage. In fact, prolonged storage reduces total phenolic content significantly. There was a significant and negative interaction between total phenolic content and storage duration when $C$. nutans was harvested as matured stems (Figure 1). The initial total phenolic content was high and tended to decrease rapidly in prolonged storage duration. However, total phenolic contents of matured leaves were lower than stem and it remained constant throughout the storage duration.

\section{Total flavonoids content}

Total flavonoids content of $C$. nutans was significantly influenced by plant parts, storage durations and their interactions (Table 1). Table 1 show that flavonoids content was higher in young plant parts than in old plant parts.
Like phenolic contents, highest flavonoids contents were observed in young leaves statistically followed by young stems. While, the lowest flavonoids contents were found in matured stems. Phenolic content of young leaves was $60 \%$ higher than that of matured leaves, and young stems contained $80 \%$ more phenolic compounds when compared with matured stems. Like phenolic contents, total flavonoids content was decreased steadily with course of time during storage. Total flavonoids contents of $C$. nutans were decreased by $>65 \%$ at 4 th day of storage. There was a negative and linear relationship between total flavonoids contents and storage duration when $C$. nutans was stored up to 4 days at $25^{\circ} \mathrm{C}$ (Figure 2). Figure 2 shows that total flavonoid in matured leaves decreases very slowly as storage duration is prolonged. Meanwhile, matured stems have significantly higher total flavonoids content than that of young stems. Total flavonoids contents in both young and matured leaves show significant, negative and linear relationship with the

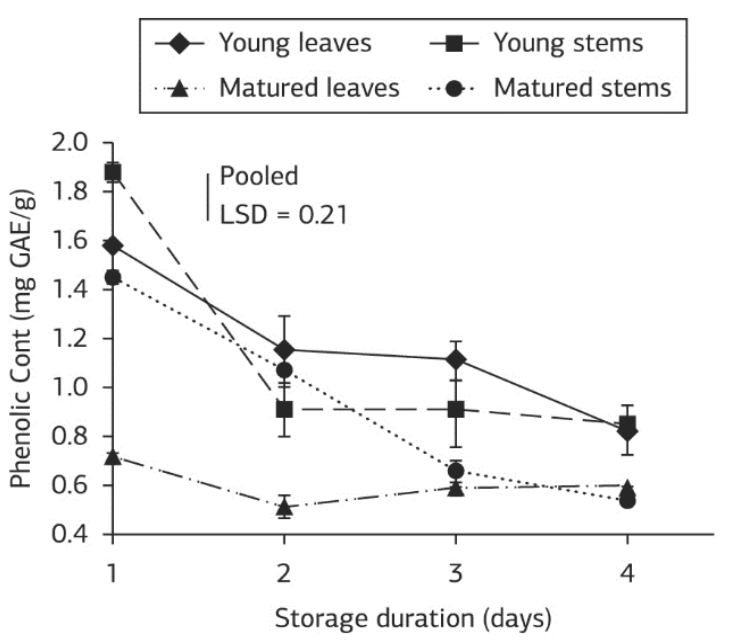

Figure 1. Relationship between phenolic content and storage duration in different plant parts of $C$. Nutans.

Table 1. Mean and interaction effects of plant parts and storage duration on phytochemical content of C. nutans

\begin{tabular}{|c|c|c|c|}
\hline Factor & $\begin{array}{l}\text { Total phenolic content } \\
\text { (mg GAE/100g) }\end{array}$ & $\begin{array}{l}\text { Total flavonoids content } \\
\text { (mg rutin/100g) }\end{array}$ & $\begin{array}{l}\text { DPPH free radical } \\
\text { scavenging (\%) }\end{array}$ \\
\hline \multicolumn{4}{|l|}{ Plant Parts (PP) } \\
\hline Young leaves & $117.000 \mathrm{a}$ & $99.465 a$ & $112.115 a$ \\
\hline Young stems & $114.417 a$ & $81.420 a b$ & $73.989 b$ \\
\hline Matured leaves & $93.417 b$ & $62.597 b c$ & $49.445 c$ \\
\hline Matured stems & $60.750 c$ & $45.557 c$ & $31.239 d$ \\
\hline \multicolumn{4}{|c|}{ Storage Duration (SD) } \\
\hline 1 & $140.917 a$ & $116.361 a$ & $101.854 a$ \\
\hline 2 & $91.417 b$ & $77.742 b$ & $76.132 b$ \\
\hline 3 & $82.167 b$ & $53.460 c$ & $56.913 c$ \\
\hline $4(\mathrm{PP} \times \mathrm{SD})$ & $71.083 c^{* *}$ & $41.476 c^{*}$ & $31.889 d^{* *}$ \\
\hline
\end{tabular}

For each factor, means within a column followed by the same letter are not significantly different by LSD at $\mathrm{p} \leq 0.05 .{ }^{*}=$ Significant at $\mathrm{p} \leq 0.05 .{ }^{* *}=$ Significant at $\mathrm{p} \leq 0.01$. 
storage duration. These are indicated by the total flavonoids contents which are linearly decreased during storage.

\section{DPPH radical scavenging activity assay}

Plant parts, storage durations and their interactions significantly influenced the DPPH of C. nutans (Table 1). It is observed from Table 1 that antioxidant power was higher in young plant than in old plant irrespective of plant parts. The highest DPPH was observed in young leaves followed by young stems. The lowest DPPH was recorded with matured stems. DPPH of young leaves was $129 \%$ higher than that of matured leaves, and young stems contained $135 \%$ more $\mathrm{DPPH}$ compared to matured stems. The DPPH was found to decrease gradually due to storage. The DPPH was reduced by almost $69 \%$ after 4 days storage. The regression analysis shows that there are significant linear, negative interactions between DPPH and storage durations of C. nutans (Figure 3). Prolonged storage duration causes progressive decrease in
DPPH of C. nutans. As illustrated in figure 3, young leaves of $C$. nutans show higher DPPH activity than that of young stems followed by matured leaves and matured stems as storage duration is prolonged.

\section{Ascorbic acid content}

Ascorbic acid content of $C$. nutans was significantly influenced by plant parts, storage durations and their interactions (table 2). It is evident from table 1 that ascorbic acid content of young leaves and matured leaves were statistically similar; but, matured stems contained $37 \%$ lower ascorbic acid than young stems. At young stage, ascorbic acid content of leaves and stems were statistically similar. Ascorbic acid content was decreased gradually with prolonged storage duration (Table 2). Ascorbic acid content was reduced by 36,42 and $53 \%$ at 2,3 and 4 days after storage when compared with 1 day storage. The regressions analysis indicates that there are significant negative interactions between ascorbic

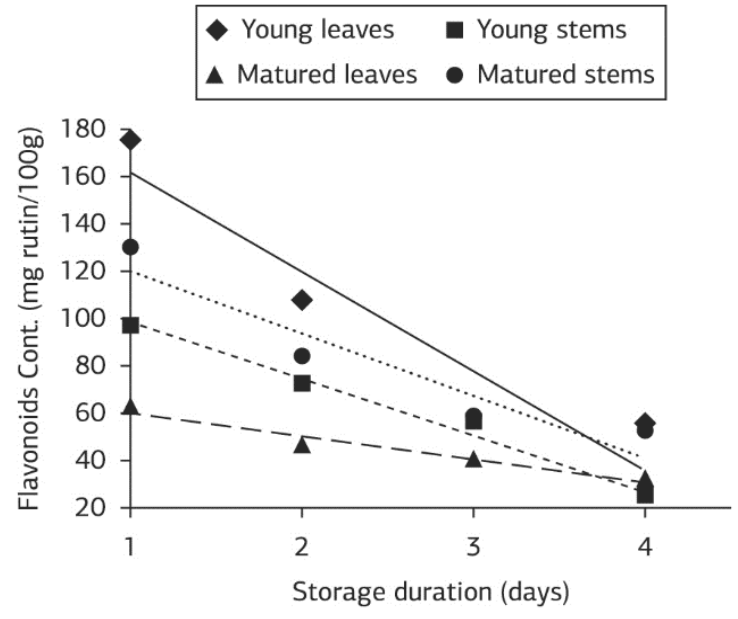

Figure 2. Relationship between total flavonoids and storage duration in different plant parts of C. Nutans.

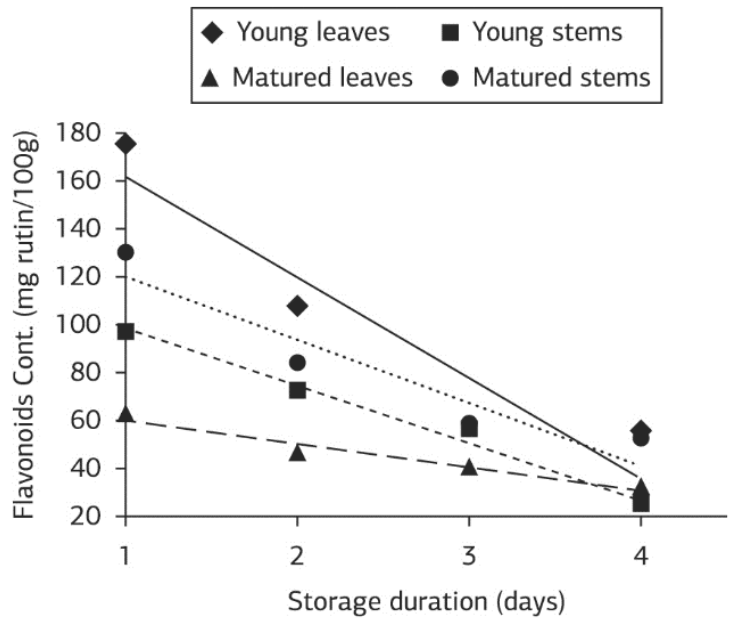

Figure 3. Relationships between DPPH radical scavenging activity assay and storage duration in different plant parts of $C$. Nutans.

Table 2. Mean and interaction effects of plant parts and storage duration on ascorbic acid and chlorophyll content of $C$. nutans

\begin{tabular}{|ccc|}
\hline Factor & Ascorbic Acid $\mathbf{( m g / 1 0 0 g )}$ & Chlorophyll Content $\mathbf{~ m g / 1 0 0 g ) ~}$ \\
\hline Plant Parts (PP) & & $64.350 \mathrm{a}$ \\
\hline Young leaves & $0.38250 \mathrm{a}$ & $42.167 \mathrm{~b}$ \\
\hline Young stems & $0.36500 \mathrm{a}$ & $37.767 \mathrm{~b}$ \\
\hline Matured leaves & $0.35667 \mathrm{a}$ & $32.267 \mathrm{c}$ \\
\hline Matured stems & $0.22833 \mathrm{~b}$ & $78.833 \mathrm{a}$ \\
\hline Storage Duration (SD) & & $50.233 \mathrm{~b}$ \\
\hline 1 & $0.49833 \mathrm{a}$ & $29.517 \mathrm{c}$ \\
\hline 2 & $0.31917 \mathrm{~b}$ & $17.967 \mathrm{~d}^{* *}$ \\
\hline
\end{tabular}

For each factor, means within a column followed by the same letter are not significantly different by LSD at $\mathrm{p} \leq 0.05 .{ }^{* *}=$ Significant at $\mathrm{p} \leq 0.01$. 
acid content and storage duration of different plant parts of C. nutans (Figure 4). However, the ascorbic acid content of the young leaves decreases rapidly due to storage duration. For young stems and matured leaves, the decrease pattern of ascorbic acid contents was similar. Meanwhile, ascorbic acid content of matured leaves decreases very slowly in respect to prolonged storage duration (Figure 4).

\section{Chlorophyll content}

Plant parts, storage durations and their interactions significantly influenced chlorophyll content of $C$. nutans (Table 1). As evident from table 1, chlorophyll content was higher in young plant parts than in old plant parts. The highest chlorophyll content was observed in young leaves which

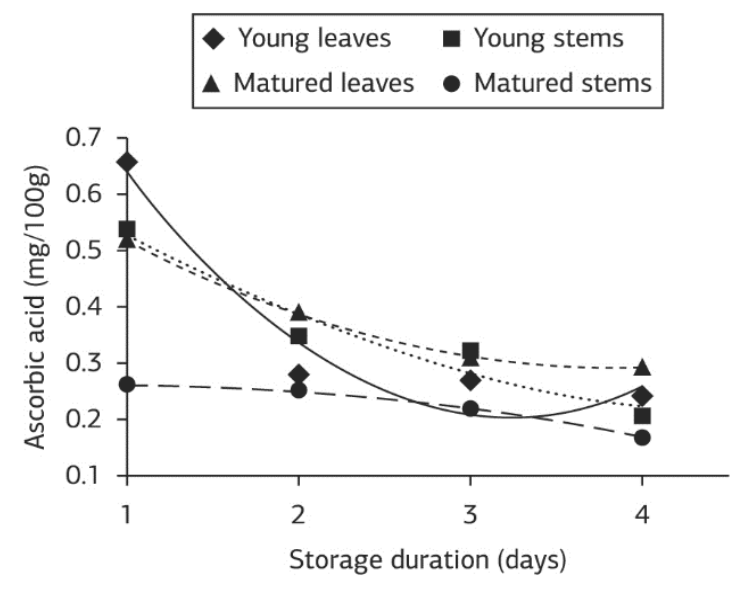

Figure 4. Relationships between ascorbic acid and storage duration in different plant parts of C. Nutans.

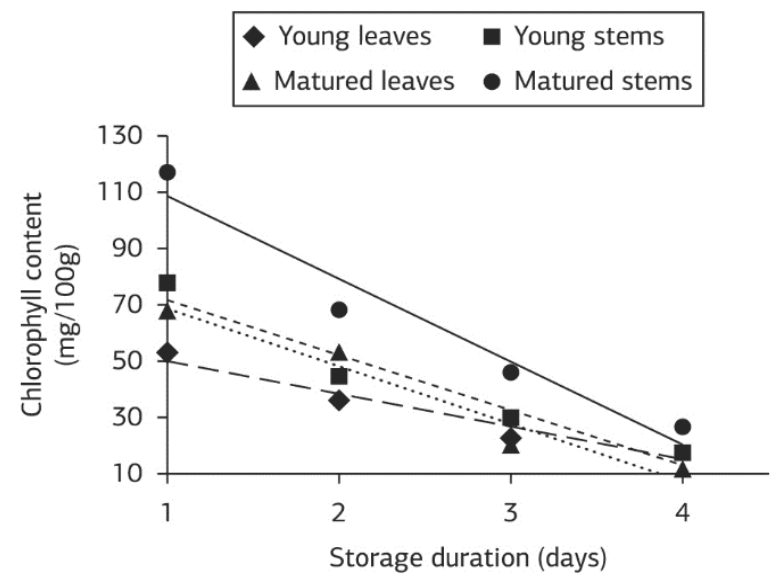

Figure 5. Relationships between chlorophyll content and storage duration in different plant parts of C. Nutans. contained $72 \%$ higher chlorophyll than matured leaves. The lowest chlorophyll content was found in matured stems. Chlorophyll content of young stems was 31\% higher than that of matured stems. Like other parameters, chlorophyll content was decreased steadily with course of time during storage. Chlorophyll content was reduced by 35, 62 and $78 \%$ at 2, 3 and 4 days after storage when compared with 1 day storage. Figure 5 confirms a significant negative linear relationship between chlorophyll content and storage duration of different plant parts of $C$. nutans (Figure 5). Decrease pattern of chlorophyll content with course of storage duration were similar for both leaves and stems irrespective of growth stages.

\section{DISCUSSION}

Current research aims at assessing the changes in phytochemical contents of $C$. nutans with respect to plant parts, growth stages and storage durations. It is evident from our findings that authentic part, proper age and storage period are very crucial for obtaining maximum pharmaceutical quality and avoiding any alternation of medicinal potency of $C$. nutans. The highest initial phenolic content was found in young leaves of $C$. nutans. This finding is in agreement with that of Males et al. (2010) who reported that $I$. candida contains higher phenolic compounds in leaves (1.031-1.423\%) compared to stem (0.411-0.516\%). Rafat et al. (2009) also recorded higher phenolic content in leaves than in stems of $A$. paniculata. Furthermore, the highest initial flavonoid content is attributed to young leaves, followed by young stems. Ghasemzadeh et al. (2014) also confirmed that phenolic contet of $C$. nutans was higher in early growth stage compared with matured stages. But, these findings are not in conformity with those of Nor Qhairul Izzreen \& Mohd Fadzelly (2013), who reported that $C$. sinensis (green tea) contains highest total flavonoids in shoots (35 mg rutin $100 \mathrm{~g}^{-1}$ ) followed by young ( $32 \mathrm{mg}$ rutin $\left.100 \mathrm{~g}^{-1}\right)$ and matured leaves $\left(21 \mathrm{mg}\right.$ rutin $\left.100 \mathrm{~g}^{-1}\right)$. The total flavonoid contents in both young and matured leaves show a significant, negative and linear relationship with the storage duration. This is the indication of linear reduction in total flavonoids contents with the advancement of storage. This result closely resembles to that of Karabegovic et al. (2012) who revealed that storage duration reduced the total flavonoids in freshly prepared herbal liquor. As stated by Prasad et al. (2010), reduction in total flavonoids during storage might be directly related with the light intensity and temperature during storage.

The DPPH activity of young leaves as well as young stems of $C$. nutans was found much higher than that of matured leaves and stems. In C. nutans, the DPPH activity in the young leaves decreased more rapidly throughout the storage durations than matured leaves. In addition, 
at the beginning of storage, there were slight changes in $\mathrm{DPPH}$ activity between young stems and matured leaves, but young stems indicated insignificant change as storage duration was prolonged compared to matured leaves which decreased very rapidly. Matured stems showed the lowest DPPH activity among the other plant parts. Rafat et al. (2009) also reported similar findings from their study with A. paniculata. Ghasemzadeh et al. (2014) on the other hand, recorded higher DPPH value in 1-year -old buds than in 6-month-old buds of $C$. nutans.

Ascorbic acid content in C. nutans varied between plant parts, and decreased with prolonged period of storage. Meanwhile, the ascorbic acid of matured leaves decreases very slowly in respect to prolonged storage duration. This finding is in concord with that of Catunescu et al. (2012) who stated that the ascorbic acid content of three herbs such as parsley (Petroselinum crispum), dill (Anethumgra veolens) and lovage (Levisticum officinale) were affected by storage duration. Lee \& Kader (2000) also confirmed that chemical processes and enzymatic oxidation of ascorbic acid is related to the storage duration and processing of the products. The anaerobic degradation might be responsible for gradual decrease in ascorbic acid content during prolonged storage period. According to Burdurlu et al. (2006), the decrease of ascorbic acid is caused by oxidation when both aerobic and anaerobic pathways are influenced by heat, light, storage duration and storage temperature. As revealed by Paśko et al. (2009), more restricted resources of younger plants would be utilized more during primary metabolic processes that are needed for growth which might result in changes in phytochemical content with course of time.

Chlorophyll content determines plant color. In the present study, highest chlorophyll content was observed in young leaves followed by young stems, and chlorophyll content decreased gradually with the advancement of storage duration. Similar findings was documented by Yamauchi \& Watada (1993) who observed that in parsley, chlorophyll content decreased by $40 \%$ during three days of storage and by $64 \%$ after five days of storage at $20{ }^{\circ} \mathrm{C}$. As Roura et al. (2000) stated, a change in chlorophyll content is associated with changes in color of the leaves. The breakdown, both in chloroplast and chlorophyll, can be viewed and measured by looking at the rate of chlorophyll losses. The degradation of chlorophyll is also related to the storage duration. The discoloration might be associated with some environmental factors like temperature, light, humidity and physiological processes such as senescence and ripening (Meir et al., 1992). Wrolstad et al. (2005), on the other hand, opined that changes in chlorophyll content are the consequence of different physicochemical changes during post-harvest processing and storage. According to Matile et al. (1997), there is one enzyme that initiates the degradation of chlorophyll, known as chlorophyllase. The senescence in leaves is caused by the activity of chlorophyllase enzyme.
Phytochemical, ascorbic acid and chlorophyll content of $C$. nutans differ among different plant parts and change due to storage. Total phytochemical content, total flavonoids content and DPPH radical scavenging activities are higher in young plants than in old plants, moreover, all those compounds are higher in leaves than in stems, and decrease gradually due to storage. In general, young plant parts contain higher amount of phytochemical, ascorbic acid and chlorophyll compared with matured parts confirming that phytochemicals content of $C$. nutans decreases when plan tends to maturity. Moreover, prolonged storage reduces phytochemical, ascorbic acid and chlorophyll content of C. nutans. Thus, our research findings confirm that $C$. nutans is a potential medicinal herb, and early harvest and fresh use of $C$. nutans is necessary to avoid its phytochemical losses. Further research focusing on the proper storage is necessary to minimize phytochemicals losses of $C$. nutans during storage.

\section{REFERENCES}

Böttcher, H., Günther, I., \& Kabelitz, L. (2003). Physiological postharvest responses of common Saint-John's wort herbs (Hypericum perforatum L.). Postharvest Biology and Technology, 29, 343-351. http://dx.doi.org/10.1016/S0925-5214(03)00057-7.

Burdurlu, H. S., Koca, N., \& Karadeniz, F. (2006). Degradation of vitamin $\mathrm{C}$ in citrus juice concentrates during storage. Journal of Food Engineering, 74, 211-216. http://dx.doi.org/10.1016/j. jfoodeng.2005.03.026.

Catunescu, G. M., Tofana, M., Muresan, C., Ranga, F., David, A., \& Muntean, M. (2012). The effect of cold storage on some quality characteristics of minimally processed parsley (Petroselinum crispum), dill (Anethum graveolens) and lovage (Levisticum officinale). Bulletin UASVM Agriculture, 69, 1843-5246.

Chelyn, J. L., Omar, M. H., Mohd Yousof, N. S., Ranggasamy, R., Wasiman, M. I., \& Ismail, Z. (2014). Analysis of flavone C-glycosides in the leaves of Clinacanthus nutans (Burm. f.) Lindau by HPTLC and HPLC-UV/DAD. The Scientific World Journal, 2014, 724267. http://dx.doi.org/10.1155/2014/724267. PMid:25405231.

Ghasemzadeh, A., Nasiri, A., Jaafar, H. Z. E., Baghdadi, A., \& Ahmed, I. (2014). Changes in phytochemical synthesis, chalcone synthase activity and pharmaceutical qualities of sabah snake grass in relation to plant age. Molecules, 19, 17632-17648. http://dx.doi. org/10.3390/molecules191117632. PMid:25361426.

Karabegovic, I.T., Vukosavljevic, P.V., Novakovic, M.M., Gorjanovic, S.Z., Dzamic, A.M., \& Lazic, M.L. (2012). Influence of the storage on bioactive compounds and sensory attributes of herbal liqueur. Journal of Nanostructure and Biostructure, 7, 1587-1598.

Khan, M. S., Nema, N., Kharya, M. D., \& Khanam, S. (2009). Chromatographic estimation of maturity based phytochemical profiling of Ipomoea mauritiana. International Journal of Phytomedicine, 1, 22-30. http://dx.doi.org/10.5138/ijpm.2009.0975.0185.05790. 
Khare, V., Kushwaha, P., Verma, S., Gupta, A., Srivastava, S., \& Rawat, A. K. S. (2012). Pharmacognostic evaluation and antioxidant activity of Urtica dioica L. Chinese Medicine, 3, 128-135. http:// dx.doi.org/10.4236/cm.2012.33021.

Lee, S. K., \& Kader, A. A. (2000). Preharvest and postharvest factors influencing vitamin $\mathrm{C}$ content of horticultural crops. Postharvest Biology and Technology, 20, 207-220. http://dx.doi.org/10.1016/ S0925-5214(00)00133-2.

Males, Z., Pilepic, K., Petrovic, L., \& Bagaric, I. (2010). Quantitative analysis of phenolic compounds of Inula candida (L.) Cass. Periodicum Biologorum, 112, 307-310.

Matile, P., Schellenberg, M., \& Vicentini, F. (1997). Localization of chlorophyllase in the chloroplast envelope. Planta, 201, 96-99. http:// dx.doi.org/10.1007/BF01258685.

Meir, S., Philosoph-Hadas, S., Gloter, P., \& Aharoni, N. (1992). Nondestuctive assessment of chlorophyll content in watercress leaves by a tristimulus reflectance colorimeter. Postharvest Biology and Technology, 2, 117-124. http://dx.doi.org/10.1016/0925-5214(92)90014-G.

Muchoki, C. N., Lamuka, P. O., \& Imungi, J. K. (2010). Reduction of nitrates, oxalates and phenols in fermented solar-dries stored cowpea (Vigna unguiculata L.) leaf vegetables. African Journal of Food Agriculture Nutrition and Development, 10, 4398-4412.

Nor Qhairul Izzreen, M. N., \& Mohd Fadzelly, A. B. (2013). Phytochemicals and antioxidant properties of different parts of Camellia sinensis leaves from Sabah Tea Plantation in Sabah, Malaysia. International Food Research Journal, 20(1), 307-312.

Paśko, P., Bartoń, H., Zagrodzki, P., Gorinstein, S., Fołta, M., \& Zachwieja, Z. (2009). Anthocyanins, total polyphenols and antioxidant activitiesin amaranth and quinoa seeds and sprouts during their growth. Food Chemistry, 115, 994-998. http://dx.doi.org/10.1016/j. foodchem.2009.01.037.

Prabhu, S., \& Barrett, D. M. (2009). Effects of storage condition and domestic cooking on the quality and nutrient content of African leafy vegetables (Cassia tora and Corchorus tridens). Journal of the Science of Food and Agriculture, 89, 1709-1721. http://dx.doi. org/10.1002/jsfa.3644.

Prasad, S., Phromnoi, K., Yadav, V. R., Chaturvedi, M. M. \& Aggarwal, B. B. (2010). Targeting inflammatory pathways by flavonoids for prevention and treatment of cancer. Journal Planta Medica, 76(11), 1044-1063. http://dx.doi.org/10.1055/s-0030-1250111. PMid:20635307.

Rafat, A., Philip, K., \& Muniandy, S. (2009). Antioxidant potential and content of phenlic compound in ethanolic extract of selected parts of Andrographis paniculata. Journal of Medicinal Plant Research, 4, 197-202.

Roura, S. I., Davidovich, L. A., \& Valle, C. E. D. (2000). Postharvest changes in fresh swiss chard (Beta vulgaris, type cycla) under different storage conditions. Journal of Food Quality, 23, 137-147. http:// dx.doi.org/10.1111/j.1745-4557.2000.tb00201.x.

Sakdarat, S., Shuyprom, A., Pientong, C., Ekalaksananan, T., \& Thongchai, S. (2009). Bioactive constituents from the leaves of Clinacanthus nutans Lindau. Bioorganic \& Medicinal Chemistry, 17, 1857-1860. http://dx.doi.org/10.1016/j.bmc.2009.01.059. PMid:19223186.

Singh, S., Singh, M., Singh, A. K., Kalra, A., Yadav, A., \& Patra, D. (2010). Enhancing productivity of indian basil (Ocimum basilicum L.) through harvest management under rainfed conditions of Subtropical North Indian Plains. Industrial Crops and Products, 32, 601-606. http://dx.doi.org/10.1016/j.indcrop.2010.07.007.

Singh, U., \& Sagar, V. R. (2010). Quality characteristics of dehydrated leafy vegetables influenced by packaging materials and storage temperature. Journal of Scientific and Industrial Research, 69, 785-789.

Sookmai, W., Ekaalaksananan, T., Pientong, C., Sakdarat, S., \& Kongyingyoes, B. (2011). The anti-papillomavirus infectivity of Clincantus nutans compounds. Srinagarind Medicinal Journal, 26, 240-242.

Thisoda, P., Rangkadilok, N., Pholphana, N., Worasuttayangkurn, L., Ruchirawat, S., \& Satayavivad, J. (2006). Inhibitory effect of Andrographis paniculata extract and its active diterpenoids on platelet aggregation. European Journal of Pharmacology, 553, 39-45. http:// dx.doi.org/10.1016/j.ejphar.2006.09.052. PMid:17081514.

Wanikiat, P., Panthong, A., Sujayanon, P., Yoosook, C., Rossi, A. G., \& Reutrakul, V. (2008). The anti-inflammatory effects and the inhibition of neutrophil responsiveness by Barleria lupulina and Clinacanthus nutans extracts. Journal of Ethnopharmacology, 116, 234-244. http:// dx.doi.org/10.1016/j.jep.2007.11.035. PMid:18207341.

Wrolstad, R. E., Acree, T. E., Decker, E. A., Penner, M. H., Reid, D. S., Schwartz, S. J., Shoemaker, C. F., Smith, D., \& Sporns, P. (Eds.). (2005). Handbook of food analytical chemistry: pigments, colorants, flavors, texture, and bioactive food components. Hoboken: Wiley-Interscience.

Yamauchi, N., \& Watada, A. E. (1993). Pigment changes in parsley leaves during storage in controlled or ethylene containing atmosphere. Journal of Food Science, 58, 616-618. http://dx.doi. org/10.1111/j.1365-2621.1993.tb04339.x.

Yong, Y. K., Tan, J. J., Teh, S. S., Mah, S. H., Ei, G. C. I., Chiong, H. S., \& Ahmad, Z. (2013). Clinacanthus nutans extracts are antioxidant with antiproliferative effect on cultured human cancer cell lines. Alternative Medicine, 2013, 1-8.

Zhang, L., Gao, Y., Zhang, Y., Liu, J., \& Yu, J. (2010). Changes in bioactive compounds and antioxidant activities in pomegranate leaves. Scientia Horticulturae, 123, 543-546. http://dx.doi.org/10.1016/j. scienta.2009.11.008. 